\title{
Variation of Quadrupole Splitting in Modified Oxyhemoglobin: A Mössbauer Effect Study
}

\author{
M. I. Oshtrakh ${ }^{\mathrm{a}}$, O. B. Milder ${ }^{\mathrm{a}, \mathrm{b}}$, V. A. Semionkin ${ }^{\mathrm{a}, \mathrm{b}}$, A. L. Berkovsky ${ }^{\mathrm{c}}$, \\ M. A. Azhigirova ${ }^{c}$, E. P. Vyazova ${ }^{c}$ \\ a Division of Applied Biophysics, Faculty of Physical Techniques and Devices for Quality Control, \\ Ural State Technical University, Ekaterinburg, 620002, Russian Federation \\ b Faculty of Experimental Physics, Ural State Technical University, \\ Ekaterinburg, 620002, Russian Federation \\ c Hematological Scientific Center of the Russian Academy of Medical Sciences, \\ Moscow, 125167, Russian Federation \\ Reprint requests to Dr. M. I. O.; Fax: +7 (3432) 74-38-84; \\ E-mail: oshtrakh@mail.utnet.ru or oshtrakh@soek.erl.e-burg.su
}

Z. Naturforsch. 55 a, 193-198 (2000); received September 11, 1999

Presented at the XVth International Symposium on Nuclear Quadrupole Interactions, Leipzig, Germany, July 25 - 30, 1999.

Human adult hemoglobin modified by both pyridoxal-5'-phosphate and glutaraldehyde in the oxy-form was studied by Mössbauer spectroscopy. Mössbauer spectra were measured at 87 and $295 \mathrm{~K}$ (hemoglobin in lyophilized form) and at $87 \mathrm{~K}$ (hemoglobin in frozen solution). The values of the quadrupole splitting for modified oxyhemoglobin were found to be lower then those of oxyhemoglobin without modifications in lyophilized form and frozen solution, respectively. The Mössbauer spectra of modified oxyhemoglobin were also analyzed in terms of the heme iron inequivalence in $\alpha$ - and $\beta$-subunits of the tetramer. Differences of the tendencies of temperature dependencies of quadrupole splitting for modified and non-modified oxyhemoglobin in lyophilized form were shown.

Key words: Hemoglobin; Mössbauer Spectroscopy; Quadrupole Spitting.

\section{Introduction}

The chemically modified hemoglobin is a useful blood substitute [1, 2]. Pyridoxal phosphate and glutaraldehyde are widely used reagents for hemoglobin modifications. Hemoglobin chemically modified by pyridoxal phosphate has lower oxygen affinity $[3,4]$ while further cross-linking by glutaraldehyde increases the oxygen affinity of modified hemoglobin $[5,6]$. It is known that pyridoxal phosphate binds to the $\mathrm{N}$-terminal $\mathrm{NH}_{2}$ groups of both $\alpha$ - and $\beta$-chains, however the change of the oxygen affinity is related with pyridoxylated $\beta$-chains [3]. The reaction of glutaraldehyde with hemoglobin is not clear yet [7]. It is known that glutaraldehyde reacts with lysines by intramolecular cross-linking of hemoglobin and polymeric cross-linking of hemoglobin molecules.

Mössbauer spectroscopy, as one of the sensitive techniques to study the heme iron electronic struc- ture, was applied to investigate the glutaraldehyde effect on hemoglobin in $[8,9]$. The authors observed a small increase of quadrupole splitting $\left(\Delta E_{\mathrm{Q}}\right)$ for cross-linked oxyhemoglobin $\left(\mathrm{HbO}_{2}\right)$ in comparison with the native one that was interpreted as variations of the heme iron stereochemistry in modified oxyhemoglobin. It should be noted that some other studies of modified hemoglobins by Mössbauer spectroscopy revealed also small differences of Mössbauer parameters. For instance, a Mössbauer effect study of deoxy- and oxyhemoglobin modified with $\mathrm{N}$ ethylmaleimide or carboxypeptidase A, respectively, demonstrated an increase of $\Delta E_{\mathrm{Q}}$ in comparison with non-modified hemoglobin $[10,11]$. Earlier we used Mössbauer spectroscopy to reveal some differences of $\Delta E_{\mathrm{Q}}$ for adult and fetal oxyhemoglobins [12 - 15], normal adult and patient's oxyhemoglobins [13, 15, $16]$, as well as for oxyhemoglobin in solution and in lyophilized form $[15,17]$. These and some other 
results demonstrated that small variations of the heme iron electronic structure and stereochemistry may be reflected by small variations of $\Delta E_{\mathrm{Q}}$ [18]. Therefore we applied Mössbauer spectroscopy for the analysis of the heme iron electronic structure and the stereochemistry in oxyhemoglobin modified by pyridoxal phosphate and glutaraldehyde.

\section{Materials and Methods}

\section{Hemoglobin Preparation}

Freshly outdated human adult red blood cells were obtained from the Blood Bank of the Hematological Scientific Center, Moscow. The washed red blood cells were lysed by hypotonic hemolysis. The stromal lipoproteins were removed by acid precipitation with $0.5 \mathrm{M}$ ascorbic acid. The precipitate was immediately separated by the tangential-flow filtration with a Pellicon crossflow filtration cell using $0.45 \mu \mathrm{m}$ and $0.22 \mu \mathrm{m}$ Durapore cassettes. The hemoglobin solution was concentrated to $200 \mathrm{~g} / \mathrm{l}$ and then dialyzed in the filtration mode against $0.9 \% \mathrm{NaCl}$ solution. The concentrated solution obtained was sterilized by passage through a sterile $0.22 \mu \mathrm{m}$ Millipore filter. Details of the hemoglobin preparation were given in [19].

The hemoglobin modification was made in the deoxygenated form. Pyridoxal-5'-phosphate (PLP) (Reanal, Hungary) was added in a 4:1 molar ratio to deoxyhemoglobin in solution. Sodium borohydride was added to the hemoglobin solution to form a covalent bond with PLP. Then the hemoglobin solution was dissolved to $5 \mathrm{~g} \%$ and glutaraldehyde (GA) (Serva, Germany) was added in a 10:1 molar ratio to the hemoglobin solution. The hemoglobin solution was dialyzed and concentrated to $8-10 \mathrm{~g} \%$ of hemoglobin and then stabilized with glucose, sorbitol, etc. Details of the hemoglobin modification were given in [20]. The methemoglobin concentration in solution was measured with an IL 282 Co-oxymeter and found to be $5 \%$. The distribution of the molecular weight of modified hemoglobin was determined by gel-chromatography on Sepharose CL-6B (Pharmacia, Sweden). The part of polymeric hemoglobin was $\sim 30 \%$, while $70 \%$ of modified hemoglobin had internal cross-linking. The average molecular weight of modified hemoglobin was $140 \mathrm{kDa}$. The oxygen dissociation curve was determined using a Hem-OScan (Aminco, USA). The value of $P_{50}$ for modified hemoglobin was $28 \mathrm{~mm} \mathrm{Hg}$ at $\mathrm{pH} 7.4, P_{\mathrm{CO}_{2}}=$
$40 \mathrm{~mm} \mathrm{Hg}, 37^{\circ} \mathrm{C}$. The biochemical and functional properties of modified hemoglobin were discussed in $[21,22]$.

Modified hemoglobin was oxygenated ( $\mathrm{Hb}(\mathrm{PLP}+$ GA) $\mathrm{O}_{2}$ ), lyophilized and stored at low temperature. Part of the lyophilized modified oxyhemoglobin was dissolved in $0.9 \% \mathrm{NaCl}$ solution and frozen by liquid nitrogen. Non-modified oxyhemoglobin $\left(\mathrm{HbO}_{2}\right)$ concentrated in solution ( $\sim 38 \mathrm{~g} \%)$ was prepared by method [23] and stored at liquid nitrogen temperature. A part of this oxyhemoglobin was also lyophilized and stored at low temperature (see [17]).

\section{Mössbauer Spectroscopy}

Mössbauer spectra were measured with the constant acceleration computerized precision spectrometer which was a part of a multi-dimension parametric Mössbauer spectrometer SM-2201 [24]. The noise of the velocity signal of the spectrometer was $1.5 \times 10^{-3} \mathrm{~mm} / \mathrm{s}$, the drift of the zero point velocity was $\pm 2.6 \times 10^{-3} \mathrm{~mm} / \mathrm{s}$, the nonlinearity of the velocity signal was $0.01 \%$, the harmonic distortion factor was $0.005 \%$ for the frequency band in the range of $0-1120 \mathrm{~Hz}$. The parabolic distortion of the spectra was not more than $0.1 \%$ from the statistical counts which were in the range from $1.5 \times 10^{6}$ to $2.6 \times 10^{6}$ counts per channel. These characteristics of the driving system permitted us to increase the sensitivity of the Mössbauer spectrometer and the quality of the measured spectra in comparison with our previous data $[12,13,16,17]$. A $2.5 \times 10^{9} \mathrm{~Bq}{ }^{57} \mathrm{Co}(\mathrm{Cr})$ source was used at room temperature.

The Mössbauer spectra of oxyhemoglobin samples in lyophilized form and in frozen solution were measured at $87 \mathrm{~K}$ using a liquid nitrogen cryostat. Additional Mössbauer spectra of lyophilized oxyhemoglobin samples were measured at room temperature. Sodium nitroprusside was used as standard absorber. Mössbauer spectra were computer fitted with a least squares procedure using a Lorentzian line shape. Mössbauer parameters (quadrupole splitting $\Delta E_{\mathrm{Q}}$, isomer shift $\delta$, line width $\Gamma$, subspectrum area $S$, absorption effect) and statistical criteria $\chi^{2}$ were determined. The values of the Mössbauer parameters of the ${ }^{57} \mathrm{Fe}$ in the beryllium window of the scintillator detector $\mathrm{Be}\left({ }^{57} \mathrm{Fe}\right)$ were determined from independent measurements and fixed during the oxyhemoglobin spectra fitting. The values of the isomer shift are given relative to $\alpha-\mathrm{Fe}$ at $295 \mathrm{~K}$. 

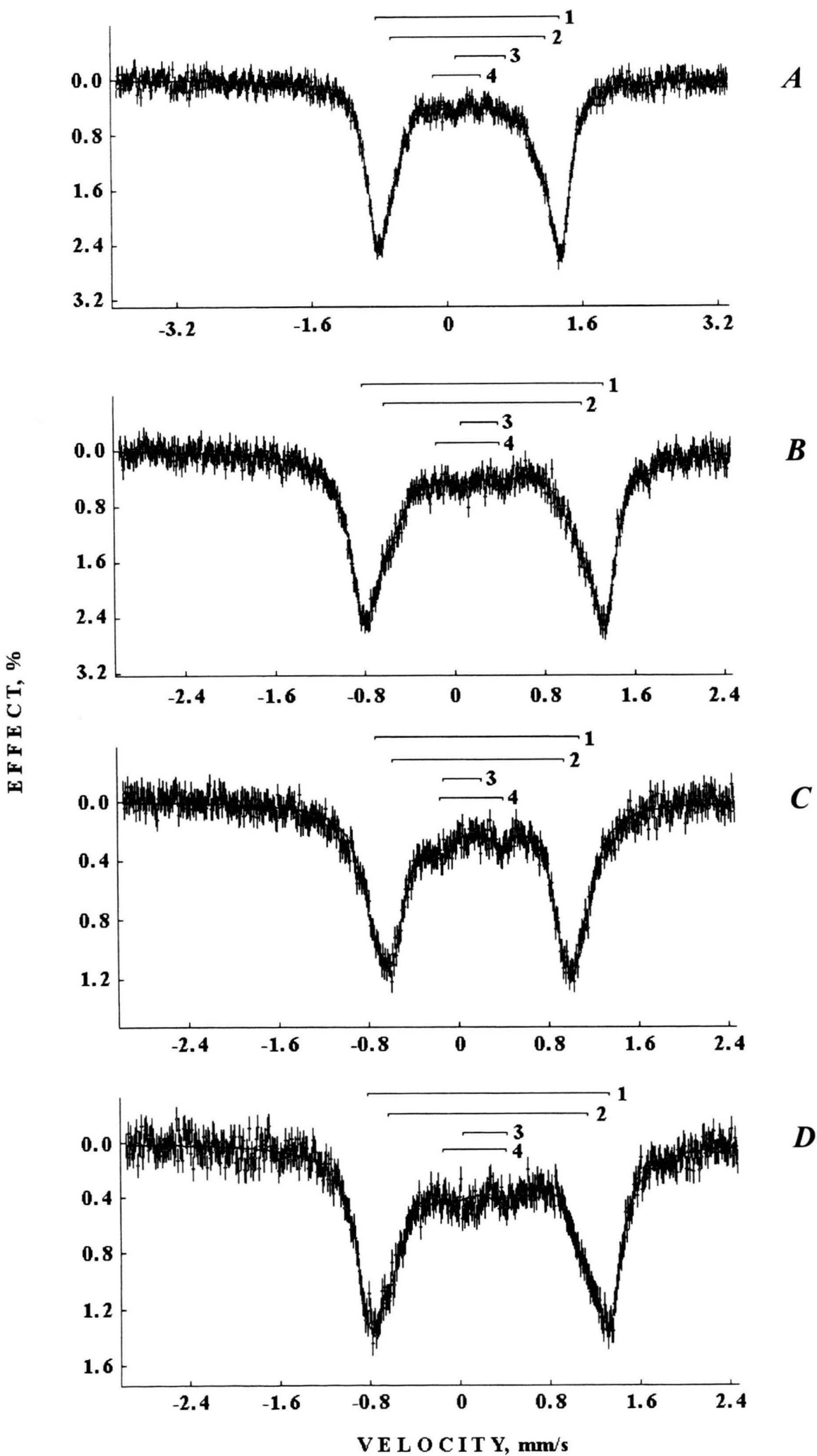

Fig. 1. Mössbauer spectra of oxyhemoglobin samples: $\mathbf{A}: \mathrm{HbO}_{2}$ in frozen solution $(T=$ $87 \mathrm{~K}) ; \quad \mathbf{B}: \mathrm{Hb}(\mathrm{PLP}+$ $\mathrm{GA}) \mathrm{O}_{2}$ in lyophilized form $(T=87 \mathrm{~K})$; $\mathbf{C}$ : $\mathrm{Hb}(\mathrm{PLP}+\mathrm{GA}) \mathrm{O}_{2}$ in lyophilized form $(T=$ $295 \mathrm{~K})$; D: $\mathrm{Hb}(\mathrm{PLP}+$ GA) $\mathrm{O}_{2}$ in frozen solution $(T=87 \mathrm{~K})$. The solid lines are the result of spectra fitting using two quadrupole doublets for oxyhemoglobin: 1: $\alpha$-subunits in tetramer; 2: $\beta$-subunits in tetramer; 3: unknown $\mathrm{Fe}^{3+}$ compound; 4: $\mathrm{Be}\left({ }^{57} \mathrm{Fe}\right)$. Vertical bars indicate statistical errors of each spectral point. 
Table 1. Mössbauer parameters of oxyhemoglobin samples (one doublet fit). ${ }^{\mathrm{a}} \mathrm{FS}$ : frozen solution, L: lyophilized form.

${ }^{b}$ Taken from [17]. ${ }^{\mathrm{c}}$ Average data for the line width of the left and right absorption peaks.

\begin{tabular}{lrcccc}
\hline Sample $^{\mathrm{a}}$ & $\begin{array}{c}T \\
{[\mathrm{~K}]}\end{array}$ & $\begin{array}{c}\Gamma \\
{[\mathrm{mm} / \mathrm{s}]}\end{array}$ & $\begin{array}{c}\delta \\
{[\mathrm{mm} / \mathrm{s}]}\end{array}$ & $\begin{array}{c}\Delta E_{\mathrm{Q}} \\
{[\mathrm{mm} / \mathrm{s}]}\end{array}$ & $\chi^{2}$ \\
\hline $\mathrm{HbO}_{2}$ (FS) & 87 & $0.377 \pm 0.028$ & $0.268 \pm 0.014$ & $2.084 \pm 0.014$ & 1.78 \\
$\mathrm{Hb}(\mathrm{PLP}+\mathrm{GA}) \mathrm{O}_{2}(\mathrm{~L})$ & 87 & $0.391 \pm 0.022$ & $0.265 \pm 0.011$ & $2.045 \pm 0.011$ & 1.86 \\
$\mathrm{Hb}(\mathrm{PLP}+\mathrm{GA}) \mathrm{O}_{2}$ (L) & 297 & $0.383 \pm 0.022$ & $0.187 \pm 0.011$ & $1.651 \pm 0.011$ & 1.08 \\
$\mathrm{Hb}(\mathrm{PLP}+\mathrm{GA}) \mathrm{O}_{2}$ (FS) & 87 & $0.425 \pm 0.022$ & $0.256 \pm 0.011$ & $1.998 \pm 0.011$ & 1.29 \\
$\mathrm{HbO}_{2}(\mathrm{~L})^{\mathrm{b}}$ & 87 & $0.398^{\mathrm{c}} \pm 0.022$ & $0.276 \pm 0.011$ & $2.139 \pm 0.011$ & 1.10 \\
$\mathrm{HbO}_{2}(\mathrm{~L})^{\mathrm{b}}$ & 297 & $0.446^{\mathrm{c}} \pm 0.022$ & $0.175 \pm 0.011$ & $1.836 \pm 0.011$ & 1.01 \\
\hline
\end{tabular}

\section{Results and Discussion}

Mössbauer spectra of oxyhemoglobin samples are shown in Figure 1. Previously we showed that Mössbauer spectra of oxyhemoglobins measured at $87 \mathrm{~K}$ had a non-Lorentzian line shape and may be fitted in two ways: using one or two quadrupole split doublets [12-14, 17]. We assumed that one quadrupole split doublet fit omitted the non-equivalence of the heme iron electronic structure and stereochemistry in $\alpha$ - and $\beta$-subunits of tetrameric oxyhemoglobin, while a fit with two quadrupole doublets took into account the inequivalence of the heme iron electronic structure and stereochemistry in $\alpha$-and $\beta$-subunits of tetrameric oxyhemoglobin. Therefore, we fitted the Mössbauer spectra of oxyhemoglobins in these two ways and compare them with data for non-modified oxyhemoglobin and previous results for lyophilized oxyhemoglobin [17]. It should be noted that all measured spectra of oxyhemoglobins contained an additional component which was related with an unknown high spin $\mathrm{Fe}^{3+}$ compound with slightly varied Mössbauer parameters. Earlier we observed an additional compound in lyophilized oxyhemoglobin at $87 \mathrm{~K}$ and related this compound to hemochromes [17]. However, we will refrain from considering the nature of this additional unknown compound and discuss the results related to oxyhemoglobin only.

\section{One Quadrupole Split Doublet Fit}

Mössbauer parameters resulting from one doublet fit are given in Table 1. The low temperature values of $\Delta E_{\mathrm{Q}}$ for modified oxyhemoglobin in both lyophilized form and frozen solution were found to be lower than that for normal one in frozen solution. Previously we found that the $\Delta E_{\mathrm{Q}}$ value of lyophilized

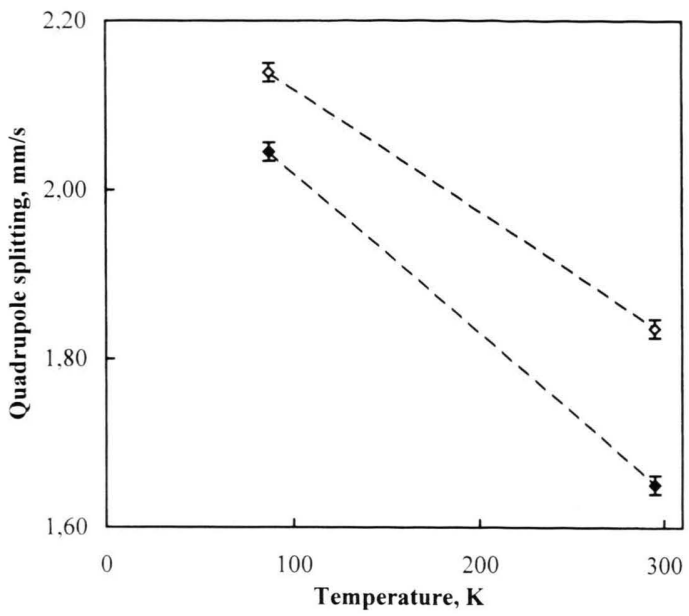

Fig. 2. Different tendencies of the temperature dependence of $\Delta E_{Q}$ for $\mathrm{Hb}(\mathrm{PLP}+\mathrm{GA}) \mathrm{O}_{2}(\diamond)$ and for $\mathrm{HbO}_{2}(\diamond)$ in lyophilized form.

normal oxyhemoglobin was higher than that of normal oxyhemoglobin in frozen solution (the difference of the $\Delta E_{\mathrm{Q}}$ values at $87 \mathrm{~K}$ was $0.055 \mathrm{~mm} / \mathrm{s}$ ). We observed the same result for modified oxyhemoglobin in lyophilized form and frozen solution (the difference of the $\Delta E_{\mathrm{Q}}$ values at $87 \mathrm{~K}$ was $0.047 \mathrm{~mm} / \mathrm{s}$ ). This fact indicates that lyophilization may affect modified and non-modified oxyhemoglobin in the same way. Lyophilization of oxyhemoglobin may induce a change of the heme iron stereochemistry that increases the distortion of the heme symmetry, leading to an increase of the electric field gradient (EFG) on the ${ }^{57} \mathrm{Fe}$ nuclei in oxyhemoglobin. A modification of hemoglobin with PLP and GA leads to another change of the protein molecule which in the oxygenated form contains the heme iron with a more symmetrical electric field and, therefore, with a lower value of the EFG on the ${ }^{57} \mathrm{Fe}$ nuclei.

A comparison of the $\Delta E_{\mathrm{Q}}$ values for modified and non-modified oxyhemoglobins in lyophilized form measured at $87 \mathrm{~K}$ and room temperature, demonstrated differences of about $0.1 \mathrm{~mm} / \mathrm{s}$ at $87 \mathrm{~K}$ and about $0.2 \mathrm{~mm} / \mathrm{s}$ at $297 \mathrm{~K}$. The different tendencies of the temperature dependence of $\Delta E_{\mathrm{Q}}$ for lyophilized forms of modified and non-modified oxyhemoglobins are shown in Figure 2. These data reflect the different electron term schemes for the heme iron in both proteins related to variations of its stereochemistry.

It should be noted that the differences of the $\chi^{2}$ values showed that the one quadrupole split doublet fit was not satisfactory for Mössbauer spec- 
Table 2. Mössbauer parameters of oxyhemoglobin samples (two doublets fit). ${ }^{a}$ FS: frozen solution, L: lyophilized form. ${ }^{b}$ Taken from [17]. ' Fixed parameter.

\begin{tabular}{|c|c|c|c|c|c|c|c|c|c|c|}
\hline Sample ${ }^{\mathrm{a}}$ & $T[\mathrm{~K}]$ & $\Gamma_{1}[\mathrm{~mm} / \mathrm{s}]$ & $\delta_{1}[\mathrm{~mm} / \mathrm{s}]$ & $\Delta E_{\mathrm{Q} 1}[\mathrm{~mm} / \mathrm{s}]$ & $\Gamma_{2}[\mathrm{~mm} / \mathrm{s}]$ & $\delta_{2}[\mathrm{~mm} / \mathrm{s}]$ & $\Delta E_{\mathrm{Q} 2}[\mathrm{~mm} / \mathrm{s}]$ & $S_{1}[\%]$ & $S_{2}[\%]$ & $\chi^{2}$ \\
\hline $\mathrm{HbO}_{2}(\mathrm{FS})$ & 87 & $0.251 \pm 0.028$ & $0.267 \pm 0.014$ & $2.173 \pm 0.014$ & $0.467 \pm 0.028$ & $0.264 \pm 0.014$ & $1.834 \pm 0.014$ & 51 & 49 & 1.15 \\
\hline $\mathrm{Hb}(\mathrm{PLP}+\mathrm{GA}) \mathrm{O}_{2}(\mathrm{~L})$ & 87 & $0.246 \pm 0.022$ & $0.264 \pm 0.011$ & $2.142 \pm 0.011$ & $0.437 \pm 0.022$ & $0.264 \pm 0.011$ & $1.757 \pm 0.011$ & 52 & 48 & 1.10 \\
\hline $\mathrm{Hb}(\mathrm{PLP}+\mathrm{GA}) \mathrm{O}_{2}(\mathrm{~L})$ & 297 & $0.280^{c}$ & $0.182 \pm 0.011$ & $1.814 \pm 0.011$ & $0.270^{c}$ & $0.190 \pm 0.011$ & $1.519 \pm 0.011$ & 48 & 52 & 1.17 \\
\hline $\mathrm{Hb}(\mathrm{PLP}+\mathrm{GA}) \mathrm{O}_{2}(\mathrm{FS})$ & 87 & $0.253 \pm 0.022$ & $0.256 \pm 0.011$ & $2.137 \pm 0.011$ & $0.422 \pm 0.011$ & $0.252 \pm 0.011$ & $1.776 \pm 0.011$ & 44 & 56 & 0.99 \\
\hline $\mathrm{HbO}_{2}(\mathrm{~L})^{\mathrm{b}}$ & 87 & $0.303^{c}$ & $0.281 \pm 0.011$ & $2.192 \pm 0.011$ & $0.526 \pm 0.022$ & $0.253 \pm 0.011$ & $1.987 \pm 0.011$ & 52 & 48 & 1.16 \\
\hline $\mathrm{HbO}_{2}(\mathrm{~L})^{\mathrm{b}}$ & 297 & $0.420^{\mathrm{c}}$ & $0.170 \pm 0.011$ & $1.959 \pm 0.011$ & $0.398^{\mathrm{c}}$ & $0.182 \pm 0.011$ & $1.721 \pm 0.011$ & 50 & 50 & 1.02 \\
\hline
\end{tabular}

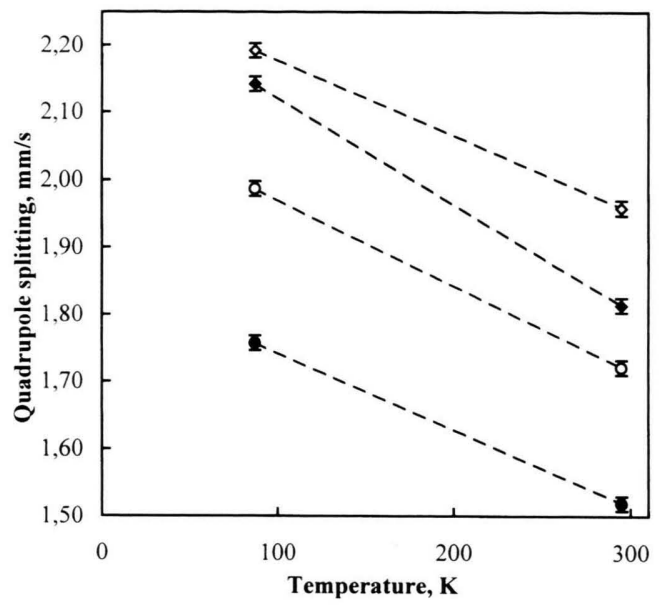

Fig. 3. Different tendencies of the temperature dependencies of $\Delta E_{\mathrm{Q} 1}$ ( $\alpha$-subunits) and $\Delta E_{\mathrm{Q} 2}$ ( $\beta$-subunits) for $\mathrm{Hb}(\mathrm{PLP}+\mathrm{GA}) \mathrm{O}_{2}$ and for $\mathrm{HbO}_{2}$ in lyophilized form. $\diamond: \alpha-$ subunits in $\mathrm{HbO}_{2}$; $\alpha$-subunits in $\mathrm{Hb}(\mathrm{PLP}+\mathrm{GA}) \mathrm{O}_{2}$; : $\beta$-subunits in $\mathrm{HbO}_{2} ; \bullet: \beta$-subunits in $\mathrm{Hb}(\mathrm{PLP}+\mathrm{GA}) \mathrm{O}_{2}$.

tra of oxyhemoglobin frozen solutions and modified oxyhemoglobin in lyophilized form measured at $87 \mathrm{~K}$ due to the asymmetrical (non-Lorentzian) absorption line shape. Previously we related this fact to the necessity of accounting for the iron electronic structure inequivalence in $\alpha$ - and $\beta$-subunits of tetrameric hemoglobin and, therefore, with the necessity to fit Mössbauer spectra of hemoglobin using two quadrupole doublets with approximately equal areas $[12,13,14,17]$.

\section{Two Quadrupole Split Doublets Fit}

Mössbauer parameters of oxyhemoglobin samples obtained from a two quadrupole doublets fit are given in Table 2. The values of $\chi^{2}$ obtained for Mössbauer spectra with asymmetry of the absorption line shape were lower than those given in Table 1. In several cases, mainly for Mössbauer spectra with symmet- rical (Lorentzian) absorption line shape, one or two line widths were fixed during the fitting procedure, like it was done earlier [12, 14, 17, 25]. For each Mössbauer spectrum the first quadrupole doublet was related to the ${ }^{57} \mathrm{Fe}$ in $\alpha$-subunits while the second quadrupole doublet was related to the ${ }^{57} \mathrm{Fe}$ in $\beta$ subunits of tetrameric oxyhemoglobin (details were given in $[17,18])$.

A comparison of the $\Delta E_{\mathrm{Q} 1}$ and $\Delta E_{\mathrm{Q} 2}$ values for various oxyhemoglobin samples measured at $87 \mathrm{~K}$ showed that larger differences of the quadrupole splitting were observed for the ${ }^{57} \mathrm{Fe}$ in $\beta$-subunits $(0.05$ - $0.16 \mathrm{~mm} / \mathrm{s}$ ), while those for the ${ }^{57} \mathrm{Fe}$ in $\alpha$-subunits were $0.02-0.04 \mathrm{~mm} / \mathrm{s}$. The differences of the quadrupole splitting for modified and non-modified oxyhemoglobin in lyophilized form measured at room temperature were $0.15 \mathrm{~mm} / \mathrm{s}$ and $0.20 \mathrm{~mm} / \mathrm{s}$ for the ${ }^{57} \mathrm{Fe}$ in $\alpha$ - and $\beta$-subunits, respectively. This fact indicates that the temperature dependencies of $\Delta E_{\mathrm{Q}}$ for $\alpha$ - and $\beta$-subunits behave differently and the heme iron has a different electronic structure in $\alpha$ - and $\beta$-subunits. The lyophilization process changes the heme iron stereochemistry in both subunits of nonmodified oxyhemoglobin in comparison with that in frozen solution. A comparison of the $\Delta E_{\mathrm{Q} 1}$ and $\Delta E_{\mathrm{Q} 2}$ values for modified oxyhemoglobin in frozen solution and lyophilized form did not reveal any differences. It was interesting to compare the tendencies of the temperature dependencies of $\Delta E_{\mathrm{Q}}$ for $\alpha$ - and $\beta$-subunits in modified and non-modified oxyhemoglobin in lyophilized form (see Figure 3). The observed differences indicate some variations of the changes of the heme iron electronic term scheme in $\alpha$ - and $\beta$ subunits, respectively, for modified and non-modified oxyhemoglobin.

\section{Conclusion}

A Mössbauer study of pyridoxylated hemoglobin cross-linked by glutaraldehyde in the oxy-form 
demonstrated that the heme iron electronic structure and stereochemistry is influenced by hemoglobin modification. Therefore, the oxygen affinity of modified hemoglobin may depend on both steric modifications of the protein and changes of the heme iron electronic structure and stereochemistry.

[1] G. S. Moss, S. A. Gould, L. R. Sehgal, and A. L. Rosen, Surgery 95, 249 (1984).

[2] Blood Substitutes, Present and Future Perspectives. E. Tsuchida, ed. Elsevier, Amsterdam 1998, p. 456.

[3] R. E. Benesh, R. Benesh, R. D. Renthal, and N. Maeda, Biochemistry 11, 3576 (1972).

[4] L. R. Sehgal, A.L. Rosen, G. Noud, H.L. Sehgal, S. A. Gould, R. Dewaskin, C. L. Rice, and G. S. Moss, J. Surg. Res. 30, 14 (1981).

[5] L. R. Sehgal, A. L. Rosen, S. A. Gould, H. L. Sehgal, and G. S. Moss, Transfusion 23, 158 (1983).

[6] M. Feola, J. Simoni, P.C. Canizaro, R. Tran, G. Raschbaum, and F. J. Behal, Surg. Gynecol. Obstet. 166, 211 (1988).

[7] D. Guillochon, L. Esclade, and D. Thomas, Biochem. Pharmacol. 35, 317 (1986).

[8] D. Guillochon, M. W. Vijayalakshmi, A. Thiam-Sow, D. Thomas, and A. Chevalier, Biochem. Cell Biol. 64, 29 (1986).

[9] A. Chevalier D. Guillochon, N. Nedjar, J. M. Piot, M. W. Vijayalakshmi, and D. Thomas, Biochem. Cell Biol. 68, 813 (1990).

[10] A. Merli, I. Ortalli, E. Papotti, and G. L. Rossi, J. de Phys. 37, C6-181 (1976).

[11] B. Balko, E. Bucci, R. L. Berger, L. J. Swarzendruber, and J. X. Montemarano, J. Biochem. Biophys. Meth. 10, 55 (1984).

\section{Acknowledgement}

This work was supported in part by the Russian Foundation for Basic Research (grant \# 97-04-49482).

[12] M.I. Oshtrakh and V.A. Semionkin, Mol. Biol. (Moscow) 19, 1310 (1985).

[13] M. I. Oshtrakh and V. A. Semionkin, FEBS Lett. 208, 331 (1986).

[14] M. I. Oshtrakh, Z. Naturforsch. 53a, 608 (1998).

[15] M. I. Oshtrakh, J. Mol. Struct. 480-481, 109 (1999).

[16] M. I. Oshtrakh and V. A. Semionkin, FEBS Lett. 257, 41 (1989).

[17] M. I. Oshtrakh, J. Inorg. Biochem. 56, 221 (1994).

[18] M. I. Oshtrakh, Z. Naturforsch. 51a, 381 (1996).

[19] A. A. Kozlov and A. L. Berkovsky, (1989) Patent SU $\mathrm{N}^{\circ} 1476646$.

[20] M. A. Azhigirova, E. P. Vyazova, M. G. Vashkevich, and Yu.A. Litvinenko, (1990) Patent SU N 321561.

[21] M. A. Azhigirova, E. P. Vyazova, and M. G. Vashkevich, Bull. Exper. Biol. Med. (Moscow) 9, 302 (1988).

[22] E. P. Vyazova, M. A. Azhigirova, and L. V. Fetisova, Bull. Exper. Biol. Med. (Moscow) 3, 254 (1990).

[23] A. A. Kozlov, A. L. Berkovsky, I. L. Smirnova, N. A. Gorbunov, and T. A. Balakina, (1985) Patent SU N ${ }^{\circ}$ $1205910 \mathrm{~A}$.

[24] S. M. Irkaev, V. V. Kupriyanov, and V. A. Semionkin, (1987) British Patent $\mathrm{N}^{\mathrm{0}} 10745$.

[25] M. I. Oshtrakh, V. A. Semionkin, B. N. Burykin, and V. I. Khleskov, Mol. Physics 66, 531 (1989). 